\title{
Effects of Amerindian Genetic Ancestry on Clinical Variables and Therapy in Patients with Rheumatoid Arthritis
}

Elena Sánchez, Ignacio García de la Torre, Mónica Sacnún, Mario Goñi, Guillermo Berbotto, Sergio Paira, Jorge Luis Musuruana, César Graf, Alejandro Alvarellos, Osvaldo D. Messina, Alejandra Babini, Ingrid Strusberg, Juan Carlos Marcos, Hugo Scherbarth, Alberto Spindler, Ana Quinteros, Sergio Toloza, José Luis C. Moreno, Luis J. Catoggio, Guillermo Tate, Alicia Eimon, Gustavo Citera, Antonio Catalán Pellet, Gustavo Nasswetter, Mario H. Cardiel, Pedro Miranda, Francisco Ballesteros, Jorge A. Esquivel-Valerio, Marco A. Maradiaga-Ceceña, Eduardo M. Acevedo-Vásquez, Conrado García García, Teresa Tusié-Luna, Bernardo A. Pons-Estel, Marta E. Alarcón-Riquelme, and the GENAR Study

ABSTRACT. Objective. To define whether Amerindian genetic ancestry correlates with clinical and therapeutic variables in admixed individuals with rheumatoid arthritis (RA) from Latin America.

Methods. Patients with RA $(n=1347)$ and healthy controls $(n=1012)$ from Argentina, Mexico, Chile, and Peru were included. Samples were genotyped for the Immunochip v1 using the Illumina platform. Clinical data were obtained through interviews or the clinical history.

Results. Percentage of Amerindian ancestry was comparable between cases and controls. Morning stiffness ( $\mathrm{p}<0.0001$, OR 0.05), rheumatoid factor (RF; $\mathrm{p}<0.0001$, OR 0.22 ), radiographic changes $(\mathrm{p}<0.0001$, OR 0.05), and higher number of criteria were associated with lower Amerindian ancestry after Bonferroni correction. Higher Amerindian ancestry correlated only with weight loss $\left(\mathrm{p}_{\text {Bonferroni }}\right.$ $<0.0001$, OR 2.85). Increased Amerindian ancestry correlated with higher doses of azathioprine $(\mathrm{p}<0.0001$, OR 163.6) and sulfasalazine $(\mathrm{p}<0.0001$, OR 48.6), and inversely with methotrexate ( $\mathrm{p}=0.001$, OR 0.35), leflunomide ( $\mathrm{p}=0.001$, OR 0.16), and nonsteroidal antiinflammatory drugs $\left(\mathrm{p}_{\text {Bonferroni }}=0.001, \mathrm{OR} 0.37\right)$. Only the presence of RF and weight loss were modified after confounders adjustment.

Conclusion. Amerindian ancestry protects against most major clinical criteria of RA, but regarding the association of RF with increased European ancestry, age, sex, and smoking are modifiers. Ancestry also correlates with the therapeutic profiles. (First Release November 1 2017; J Rheumatol 2017;44:1804-12; doi:10.3899/jrheum.160485)

Key Indexing Terms:

RHEUMATOID ARTHRITIS LATIN AMERICAN ADMIXTURE AMERINDIAN SMOKING

From the Department of Neurology, Icahn School of Medicine at Mount Sinai, New York, New York, USA; Departamento de Inmunología y Reumatología, Hospital General de Occidente y Universidad de Guadalajara, Zapopan; Unidad de Investigación “Dr. Mario Alvizouri Muñoz” Hospital General "Dr. Miguel Silva,” Secretaría de Salud de Michoacán, Morelia; Servicio de Reumatología del Departamento de Medicina Interna, Facultad de Medicina y Hospital Universitario "Dr. José Eleuterio González," Universidad Autonoma de Nuevo León, Monterrey; Departamento de Reumatología, Hospital General de Culiacán, Culiacán; Unidad de Reumatología, Hospital General de México "Dr. Eduardo Liceaga”; Unidad de Biología Molecular y Medicina Genómica from Instituto de Investigaciones Biomédicas de la Universidad Nacional Autónoma de México, and Instituto Nacional de Ciencias Médicas y Nutrición Salvador Zubirán, Mexico City, Mexico; Hospital Provincial de Rosario; Instituto Lucha Antipoliomielítica de Rosario (ILAR); Hospital Escuela Eva Perón, Granadero Baigorria; Hospital José Maria Cullen; Hospital J.B. Iturraspe, Santa Fe; Hospital San Martín, Paraná; Hospital Privado de Córdoba; Hospital Italiano de Córdoba; Instituto Reumatológico Strusberg, Córdoba; Hospital Cosme Argerich; Hospital Italiano de Buenos Aires; Organización Médica
Integral; Centro de Educación Médica e Investigaciones Clínicas (CEMIC); Instituto de Rehabilitación Psicofísica (IREP); Hospital Bernardino Rivadavia; Hospital de Clínicas de Buenos Aires, Buenos Aires; H.I.G.A. San Martín, La Plata; H.I.G.A. Oscar E. Alende, Mar del Plata; Centro Medico Privado de Reumatología; FUNIPSE, San Miguel de Tucumán, Tucumán; Hospital Interzonal San Juan Bautista, Catamarca; Hospital G. Rawson, San Juan; Sanatorio Parque, Rosario, Argentina; Facultad Medicina Occidente, and Facultad de Medicina Campus Centro, Universidad de Chile, Santiago de Chile, Chile; Servicio de Reumatología, Hospital Nacional Guillermo Almenara I, EsSalud y Facultad de Medicina, Universidad Nacional Mayor de San Marcos, Lima, Perú; GENYO, Centro Pfizer-Universidad de Granada-Junta de Andalucía de Genómica e Investigación Oncológica, Granada, Spain; Unit of Chronic Inflammatory Diseases, Institute of Environmental Medicine, Karolinska Institutet, Stockholm, Sweden.

E. Sánchez, PhD, Department of Neurology, Icahn School of Medicine at Mount Sinai; I. García de la Torre, MD, Departamento de Inmunología y Reumatología, Hospital General de Occidente y Universidad de Guadalajara; M. Sacnún, MD, Hospital Provincial de Rosario; M. Goñi, MD, Instituto Lucha Antipoliomielítica de Rosario (ILAR); G. Berbotto, 
MD, Hospital Escuela Eva Perón; S. Paira, MD, Hospital José Maria Cullen; J.L. Musuruana, MD, Hospital J.B. Iturraspe; C. Graf, MD, Hospital San Martín; A. Alvarellos, MD, Hospital Privado de Córdoba; O.D. Messina, MD, Hospital Cosme Argerich; A. Babini, MD, Hospital Italiano de Córdoba; I. Strusberg, MD, Instituto Reumatológico Strusberg; J.C. Marcos, MD, H.I.G.A. San Martín; H. Scherbarth, MD, H.I.G.A. Oscar E. Alende; A. Spindler, MD, Centro Medico Privado de Reumatología; A. Quinteros, MD, FUNIPSE; S. Toloza, MD, Hospital Interzonal San Juan Bautista; J.L. Moreno, MD, Hospital G. Rawson; L.J. Catoggio, MD, Hospital Italiano de Buenos Aires; G. Tate, MD, Organización Médica Integral; A. Eimon, MD, CEMIC; G. Citera, MD, IREP; A. Catalán Pellet, MD, Hospital Bernardino Rivadavia; $G$. Nasswetter, MD, Hospital de Clínicas de Buenos Aires; M.H. Cardiel, MD, Unidad de Investigación "Dr. Mario Alvizouri Muñoz" Hospital General “Dr. Miguel Silva,” Secretaría de Salud de Michoacán; P. Miranda, MD, Facultad Medicina Occidente, Universidad de Chile; F. Ballesteros, MD, Facultad de Medicina Campus Centro, Universidad de Chile; J.A. Esquivel-Valerio, MD, Servicio de Reumatología del Departamento de Medicina Interna, Facultad de Medicina y Hospital Universitario “Dr. José Eleuterio González," Universidad Autonoma de Nuevo León; M.A. Maradiaga-Ceceña, MD, Departamento de Reumatología, Hospital General de Culiacán; E.M. Acevedo-Vásquez, MD, Servicio de Reumatología, Hospital Nacional Guillermo Almenara I, EsSalud y Facultad de Medicina, Universidad Nacional Mayor de San Marcos; C. García García, MD, Unidad de Reumatología, Hospital General de México "Dr. Eduardo Liceaga”; T. Tusié-Luna, MD, PhD, Unidad de Biología Molecular y Medicina Genómica from Instituto de Investigaciones Biomédicas de la Universidad Nacional Autónoma de México, and Instituto Nacional de Ciencias Médicas y Nutrición Salvador Zubirán; B.A. Pons-Estel, MD, Sanatorio Parque; M.E. Alarcón-Riquelme, MD, PhD, GENYO, Centro Pfizer-Universidad de Granada-Junta de Andalucía de Genómica e Investigación Oncológica, and Unit of Chronic Inflammatory Diseases, Institute of Environmental Medicine, Karolinska Institutet. Dr. Juan Carlos Marcos has died.

Address correspondence to Dr. M.E. Alarcón-Riquelme, GENYO, Centre for Genomics and Oncological Research: Pfizer, University of Granada, Andalusian Regional Government, PTS Granada, Avenida de la

Ilustración 114, 18016, Granada, Spain.

E-mail:marta.alarcon@genyo.es,marta.alarcon@ki.se

Accepted for publication July 20, 2017.

Rheumatoid arthritis (RA) is an inflammatory disease affecting and destroying the joints and leading to significant disability. In recent years, genetic studies of RA have identified a large number of susceptibility loci, primarily in patients who are positive for anticyclic citrullinated peptide antibodies (anti-CCP) of European and Asian ancestries ${ }^{1-15}$. The prevalence of RA does vary across populations, but this variation is dependent on the ancestral predominance in a given geographic region. In Europe ${ }^{16}$ and in large cities of Latin America ${ }^{17}$, the prevalence is around $0.3-0.5 \%$. In areas where Amerindian ancestry is more common, a higher prevalence has been reported ${ }^{18,19}$. Our group performed the first genetic study of RA in a large set of patients and controls from several countries in Latin America with enriched Amerindian ancestry, in which we detected loci in chromosomes 1 (TNFRSF 14-MMEL1), 6 (HLA class II region), 12, 13 (ENOX1), and $22^{20}$. While the HLA region has been the main genetic determinant, more recently, the contribution of specific amino acids done through imputation has shown similarities across populations, and rare variants have also been shown to have a role, albeit minor in the genetic contribution $^{12,21,22}$. Studies in the North European and North
American populations have supported that the presence of anti-CCP and some of the most important loci such as the HLADRB1 and PTPN22 increase risk for RA in the presence of smoking $23,24,25,26,27,28$, although more recently, the role of gingivitis and changes in the oral microbiota as well as other environmental factors may also modulate risk ${ }^{29,30,31}$. More recently, the use of drug discovery approaches based on genetics and genomics has started to bear fruit, and new studies may be able to repurpose drugs toward orphan connective tissue diseases using similar approaches ${ }^{32}$.

The admixture between ancestral populations may modify the risk for disease, but it may also be subject to local environments. At the discovery of the Americas, a 500-year admixture process started, primarily between the Spanish Conquistadores and the Amerindian population. This admixture varies geographically but is primarily concentrated in Mexico, Peru, Bolivia, Paraguay, Chile, and the countries of Central America, and less so in Argentina or Uruguay, where a more recent and important migration from Southern and Northern Europe occurred toward areas populated by nomadic indigenous groups.

We have also studied systemic lupus erythematosus (SLE) in these populations, and interestingly we found that more Amerindian ancestry increases the risk of developing SLE at a younger age ${ }^{33}$. In addition, we found that increased Amerindian ancestry was associated with most severe clinical manifestations of SLE, particularly renal disease, although we were unable to separate the socioeconomic effect of the Amerindian ancestry with the development of renal disease ${ }^{34}$. Here we wanted to investigate whether similar ancestral correlations could be found when using genetic ancestry as measured with a large number of single-nucleotide polymorphisms that serve as admixture informative markers, instead of self-reported ancestry in RA. Our results revealed quite the opposite of what we observed in SLE. The most important clinical variables of RA, such as morning stiffness or radiographic changes indicating the presence of erosions, associate with less Amerindian ancestry, and consequently higher European ancestry.

Response to therapy may also be determined by ancestry, although the correlations may be subject to specific environments that correlate with ancestry more than the genetic ancestry itself ${ }^{34}$. Therefore, knowledge of the ancestry of individuals and their careful study is of great importance to determine differences across individuals that may help implement the best therapies in a personalized fashion.

To our knowledge, our study defines for the first time the role of ancestry in an admixed population with RA, data that may use genetic ancestry as a way to determine disease prognosis.

\section{MATERIALS AND METHODS}

Samples and genotyping. A total of 2357 samples were collected through a multicenter collaboration known as "Genomica de Artritis Reumatoide"

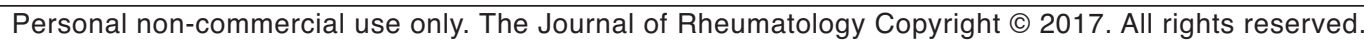


(GENAR), involving centers in Argentina, Mexico, Chile, and Peru (GENAR members and their locations are in Appendix 1). The inclusion criteria for the samples were previously described ${ }^{20}$. Physicians subjectively assessed ethnicity of the individuals. After clinical and sociodemographic data collection, a total of 1341 samples were from Argentina (756 RA cases and 585 Controls), 498 samples from Mexico (252 RA cases and 246 controls), 316 samples from Peru (218 RA cases and 98 controls), 172 samples from Chile (109 RA cases and 63 controls), and 30 samples were from other different Latin American countries (11 RA cases and 19 controls). Informed consent was obtained from all subjects. The study was approved by each of the institutional committees of the sites where the samples came from for the project "Estudio del Genoma en Pacientes Latinoamericanos con artritis reumatoidea”: Comité de Docencia e Investigación del Hospital Provincial de Rosario, Argentina; Comité de Docencia e Investigación Sanatorio Parque, Rosario Argentina for the project; Comité de docencia e investigación Hospital San Martín, Paraná, Entre Ríos, Argentina, with the same title; Hospital General "Dr. Miguel Silva," Morelia, Michoacán, Mexico; Comité de ética de la Facultad de Medicina de la UANL y Hospital Universitario “Dr. José E. González” no. RE08-001; Comité Docencia e Investigación de la Organización Médica de Investigación, Buenos Aires, Argentina; Comité de Docencia e Investigación Hospital Rawson, San Juan, Argentina; Comité de Etica Hospital General de Culiacán "Dr. Bernardo J. Gastelum"; Comité de ética de Investigación en Seres Humanos, Universidad de Chile, Facultad de Medicina; Enseñanza, Investigación, Capacitación y Etica Hospital General de Occidente; Comité de Etica de Protocolos de Investigación, Hospital Italiano de Buenos Aires, Argentina; Comité de Bioética Hospital Bernardino Rivadavia, Buenos Aires, Argentina; Comité de Docencia e Investigación, Hospital Provincial Dr. José M. Cullen, Santa Fé, Argentina; Comité de Etica, Docencia e Investigación Hospital Angel C. Padilla, Tucumán, Argentina; Comité de Bioética, HIEMIHIGA, Mar del Plata, Argentina, Departamento de Docencia e Investigación, Hospital Privado Centro Médico de Córdoba, Argentina; Comité de Bioética, Hospital General de Agudos “C. Argerich," Buenos Aires, Argentina; Comité de Etica en Investigación, CEMIC, Buenos Aires, Argentina; Comité de Etica Cientifico, CEC del S.S.M. Oriente; "Comité de Investigación, EsSalud, no. 02; and Dirección de Investigación Hospital General de México, No. DI/03/08/308.

Genotyping was performed using an Illumina Infinium High-Density BeadArray designed by the Immunochip Consortium ${ }^{35}$. Genomic DNA extracted from the peripheral blood samples was genotyped (as a service of the Robert S. Boas Center for Genomics and Human Genetics, Feinstein Institute for Medical Research, Manhasset, New York, USA) according to Illumina protocols. Genotype calling and quality control filters have been previously described ${ }^{20}$.

Clinical and treatment data. The following 7 criteria for classification of RA data were collected for each patient: morning stiffness, radiographic changes, presence of 3 or more affected joints, symmetrical RA, presence of subcutaneous nodules, hand joints affected, and presence of positive rheumatoid factor (RF). In addition, data from several extraarticular manifestations were also collected. Therapeutic data included administration of steroidal and nonsteroidal antiinflammatory drugs (NSAID), prednisone, chloroquine, hydroxychloroquine, methotrexate (MTX), leflunomide (LEF), sulfasalazine (SSZ), gold salts, azathioprine (AZA), minocycline, cyclosporine (CSA), and biologic agents. Table 1 shows the total number of individuals available for each analysis.

Sociodemographic data. The following sociodemographic data were collected for the patients with RA and controls: physician-assessed ancestry, sex, age, smoking habits, formal education in years, medical coverage (which could be public, institutional, partial or complete, private partial or complete, or none), and socioeconomic level as defined by the Graffar scale (high, medium, low, or poverty). The socioeconomic status was determined by questionnaires including information on 6 categories: family monthly income, occupation of the head of the household, percentage of family income spent on food, type and characteristics of residence (owner occupied,
Table 1. Description of data and number of individuals available for analysis. Values are $\mathrm{n}$.

\begin{tabular}{lcc}
\hline Variables & RA Patients & Controls \\
\hline Genotyping after QC & 1347 & 1012 \\
Sex & 1346 & 1011 \\
Socioeconomic status & 1280 & 895 \\
Yrs of education & 1269 & 898 \\
Medical coverage & 1265 & 890 \\
Place of residence & 1276 & 824 \\
Smoking habits & 1267 & 816 \\
Age, yrs & 1311 & 929 \\
Age of onset & 1319 & N/A \\
Age at diagnosis & 1319 & N/A \\
Anti-CCP & 1128 & N/A \\
ACR criteria & 1319 & N/A \\
Extraarticular manifestations & 1319 & N/A \\
Treatment & 1319 & N/A \\
\hline
\end{tabular}

RA: rheumatoid arthritis; QC: quality control; anti-CCP: anticyclic citrullinated peptide antibodies; ACR: American College of Rheumatology; N/A: non-applicable.

rented, or shared with extended family), place of residence, and the presence of chronic illnesses in other family members. Points are given for each category, and the sum is used to assign participants to 1 of 6 socioeconomic status bands (lowest to highest). Age at onset and age at diagnosis data were also collected in patients with RA.

Stratification analyses for ancestry estimation. To estimate the admixture proportion in our samples, we performed analyses with Structure version 2.2 software that was done in our previous publication and has been readily described in detail ${ }^{20}$. The data were used here to combine with the sociodemographic, clinical, and therapeutic information available.

Genetic risk score (GRS) of the HLA. The shared epitope (SE) has been inferred by imputation of the HLA classical alleles using the HiBAG software package with published variable estimates from Hispanic ancestries ${ }^{36}$. The SE include the HLA-DRB1 alleles $* 01: 01, * 01: 02, * 04: 01$, $* 04: 04, * 04: 05, * 04: 08, * 04: 10$, and *10:01. The estimated OR in our data was 2.00 , and was used to weight the GRS.

Statistical analysis. Stratification analysis, principal component analysis, and correlation between eigenvector and ancestry proportions were previously described ${ }^{20}$. Comparisons of the individual ancestry estimates between women and men and between patients with RA and controls were performed by means of Student $t$ test and chi-square test using GraphPad Prism software, version 6.0. Logistic regression analyses were performed to compare clinical manifestations or treatments and ancestry, and for adjustment for age, sex, and smoking using Stata/SE software, version 10.1. The Mann-Whitney U test was used to test association between presence of anti-CCP and ancestry using GraphPad Prism software, version 6.0 Bonferroni correction was used to correct for multiple testing where, for the clinical variables, a cutoff of $0.05 / 55$ or $p \geq 0.0009$ was considered nonsignificant, while for the therapeutics, a value of $0.05 / 13 \mathrm{p} \geq 0.003$ was considered not significant.

\section{RESULTS}

Sociodemographic data. A total of 1347 RA cases from Latin America were identified and genotyped for the Illumina Immunochip version 1 . Serum was also obtained from a group of patients in whom anti-CCP antibodies were determined. Of the patients, $86.8 \%$ were women with a mean age of 57.9 years $(\mathrm{SD}+13.3)$ and a mean age of onset of 41.7 
years (SD +13.0). Individuals with more than $10 \%$ Asian or African ancestry were excluded. The mean European ancestry was $43.30 \%$, Amerindian 51.5\%, Asian 2.2\%, and African 3\%.

When we analyzed the socioeconomic information in our case-control cohort using linear regression, we found that healthy control individuals living in rural areas had a higher Amerindian admixture ( $\mathrm{p}=0.008$; Figure 1A). However, no differences between living in rural or urban areas were found among the RA cases $(\mathrm{p}=\mathrm{ns}$; Figure 1B). The majority of Peruvian individuals (87.4\%) had a similar medical coverage (institutional complete). To avoid any bias in our analysis, we have excluded the Peruvian individuals to test any association between Amerindian ancestry and medical coverage,
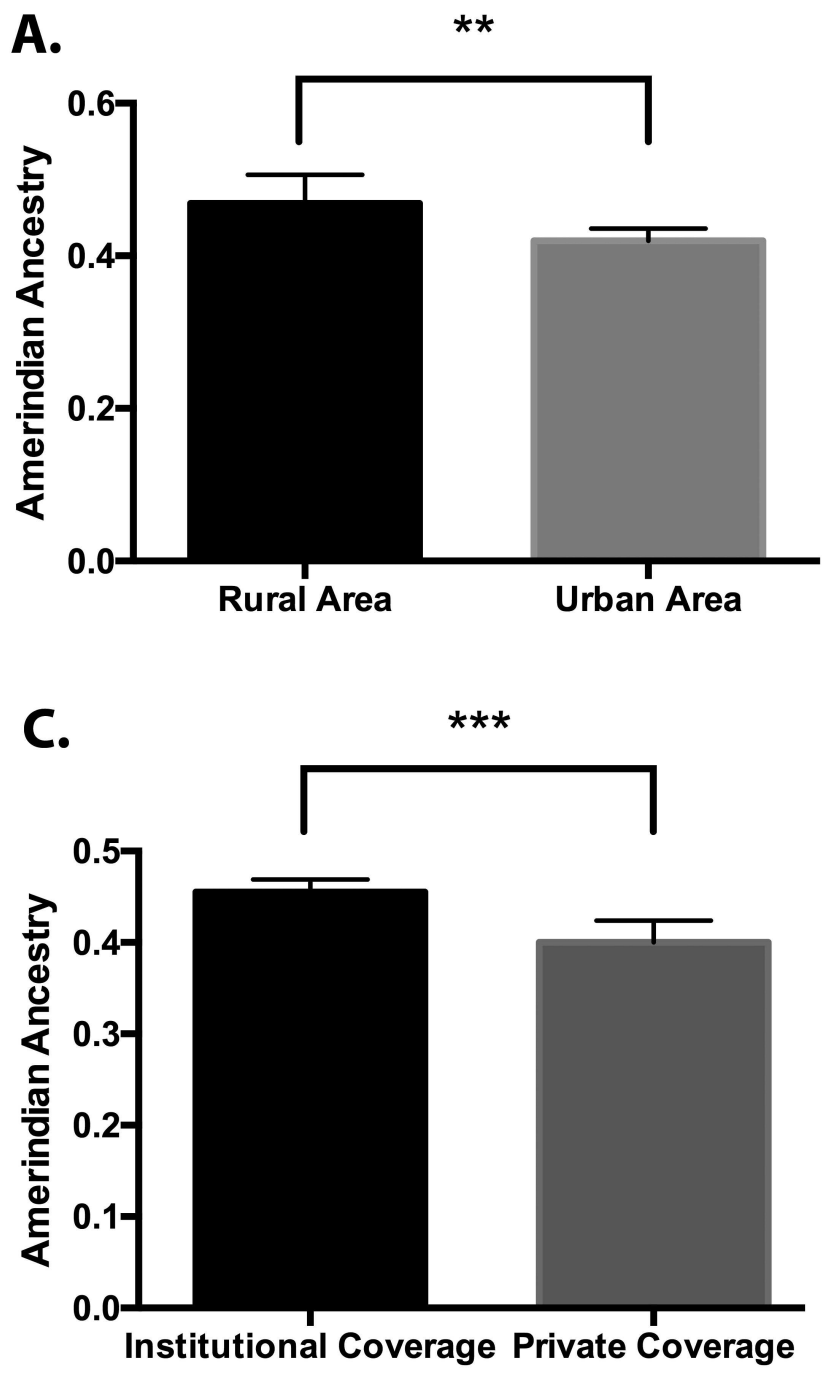

and we have found that in general, and as expected, a higher medical coverage was strongly associated with a lower Amerindian admixture $(\mathrm{p}<0.0001$; Figure 1C). No significant differences were observed in the Argentinean population in either cases or controls when we compared ancestry data with socioeconomic level (Figure 1D). However, the mean Amerindian admixture in our cohorts from Mexico, Chile, and Peru was higher in those individuals who had lower socioeconomic status $(\mathrm{p}=0.0012)$ as measured using the Graffar scale (Figure 1D). Although we observed a trend of association between Amerindian proportion and years of education in RA cases, those differences were not statistically significant ( $\mathrm{p}=0.1$, data not shown). In addition, no significant differences were found between smoking habits and
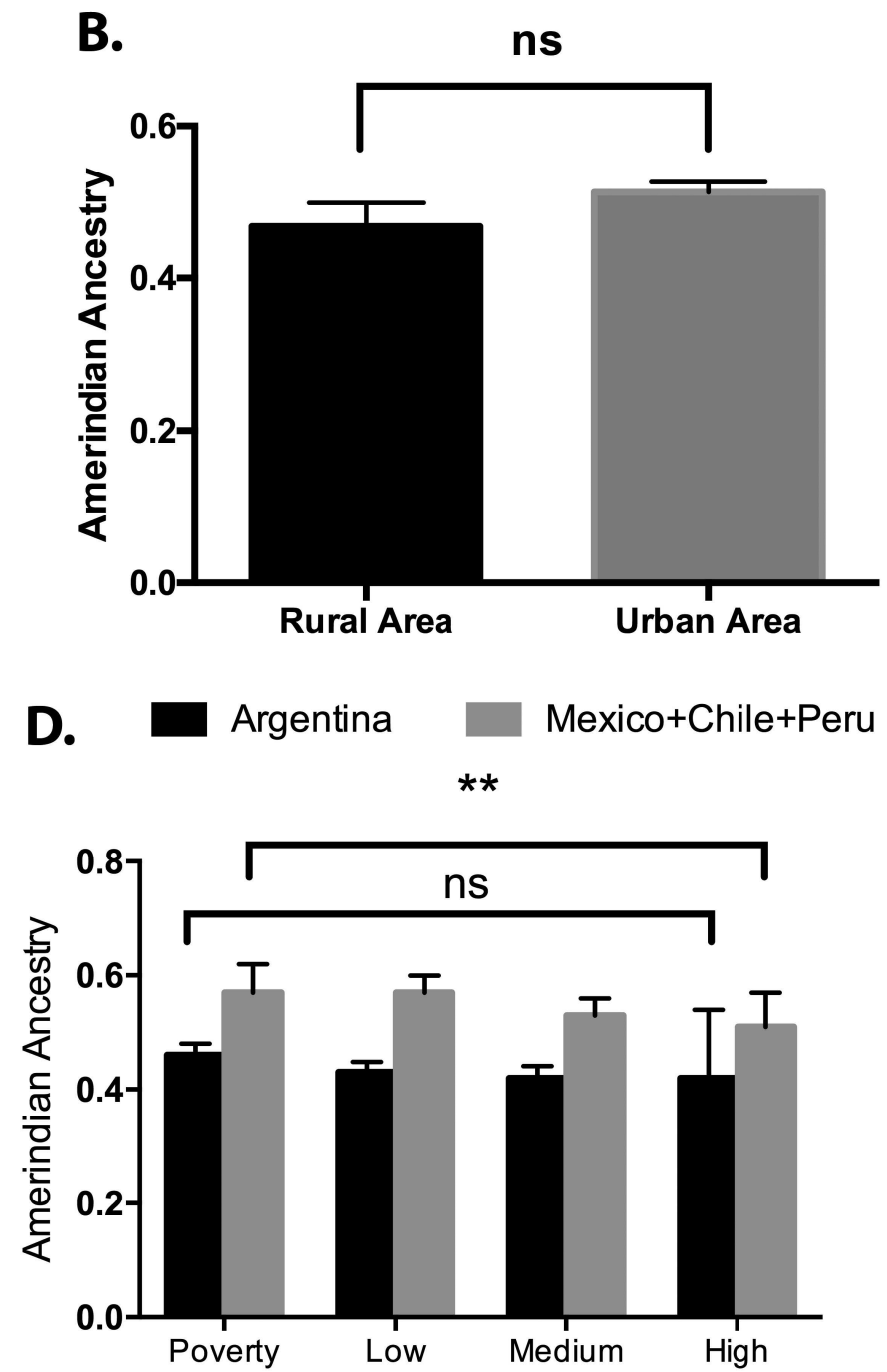

Figure 1. Linear regression analysis between sociodemographic variables and global proportion of Amerindian ancestry in the study cohort. (A) Analysis between healthy control individuals living in rural areas (solid black column) compared with healthy control individuals living in urban areas (solid gray column; $\mathrm{p}=0.008$ ). (B) Linear regression analysis between patients with RA living in rural areas (solid black column) compared with patients with RA living in urban areas (solid gray column; $\mathrm{p}=\mathrm{ns}$ ). (C) Reduced Amerindian ancestry is associated with reduced medical coverage ( $\mathrm{p}<0.0001$ ). (D) No significant differences between socioeconomic levels and Amerindian ancestry in Argentinean population (solid black column; $\mathrm{p}=\mathrm{ns}$ ). Significant association was found between socioeconomic levels and Amerindian ancestry in Mexican, Chilean, and Peruvian populations $($ solid gray column; $\mathrm{p}=0.0012)$. $* * \mathrm{p}=0.008$. $* * * \mathrm{p}<0.0001$. RA: rheumatoid arthritis; ns: not significant. 
Amerindian ancestry in Argentinean, Mexican, or Chilean individuals in either RA cases or controls, except for smoking habit that was strongly correlated with lower Amerindian ancestry in our set from Peru ( $<<0.0001$; Figure 2).

Clinical manifestations. Table 2 shows the $\mathrm{p}$ values and OR when analyzing clinical variables and ancestry. OR below 1 refer to lower Amerindian ancestry and above 1 to lower European ancestry. Only significant results following Bonferroni correction are shown.

We first analyzed the RA classification criteria. Individually, reduced Amerindian ancestry correlated with risk for morning stiffness $(\mathrm{p}<0.0001$, OR $0.05,95 \%$ CI $0.02-0.12$ ), positive RF ( $\mathrm{p}<0.0001$, OR $0.22,95 \%$ CI $0.11-0.44)$, as well as radiographic changes $(\mathrm{p}<0.0001$, OR $0.05,95 \%$ CI $0.03-0.10$ ). Presence of subcutaneous nodules showed association that was not significant following Bonferroni correction $(\mathrm{p}=0.005$, OR $0.40,95 \%$ CI $0.21-0.75)$. Although not significant according to Bonferroni, presence of 3 or more affected joints $(\mathrm{p}=0.006$, OR 0.15 , 95\% CI 0.04-0.58) and symmetrical RA ( $\mathrm{p}=0.006$, OR 0.21 , 95\% CI 0.07-0.64) were associated with reduced Amerindian ancestry. In fact, the lower the Amerindian ancestry, the higher the number of criteria $(\mathrm{p}<0.0001)$ as determined by logistic regression and shown in Figure 3.

We also analyzed the presence of anti-CCP antibodies. Because the number of samples available was lower than the total number of patients $(\mathrm{n}=1128)$, the association was not significant, but showed a tendency toward the same direction as the criteria ( $\mathrm{p}=0.13$, OR $0.58,95 \%$ CI $0.28-1.19)$.

Other clinical extraarticular manifestations not included in the American College of Rheumatology criteria that were also associated with lower Amerindian ancestry were the presence of atlantoaxial subluxation $(\mathrm{p}=0.008$, OR 0.12 , $95 \%$ CI $0.03-0.58)$, periungual infarction $(\mathrm{p}=0.03$, OR 0.05 , 95\% CI 0.0004-0.78), and thrombocytosis $(\mathrm{p}=0.008$, OR $0.17,95 \%$ CI $0.05-0.63$; Table 2), but they did not remain significant following Bonferroni correction.

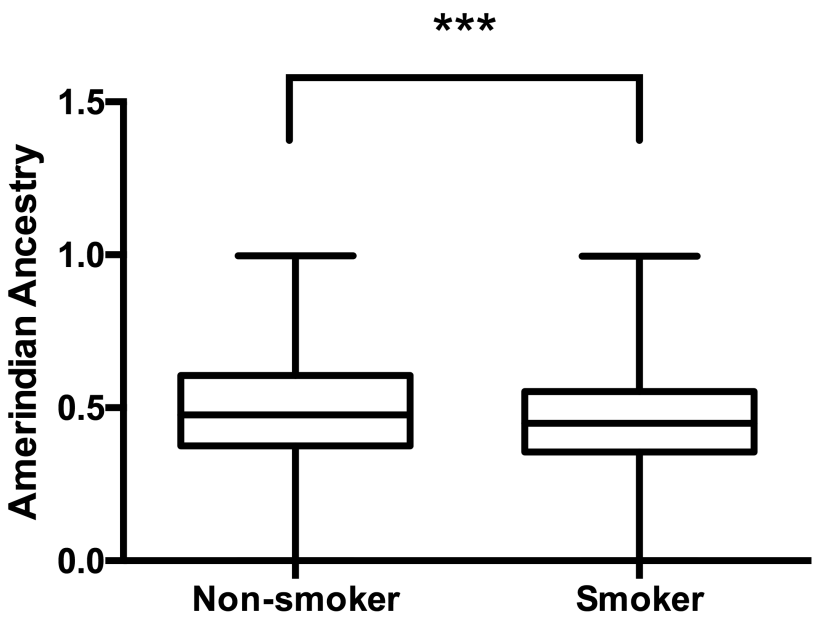

Figure 2. Association between lower Amerindian ancestry and smoking habit. $* * * \mathrm{p}<0.0001$.
On the other hand, a few more general manifestations were associated with higher Amerindian ancestry, with the exception of weight loss; they were not significant after Bonferroni correction (Table 2). These were fatigue $(\mathrm{p}=0.002$, OR $2.53,95 \%$ CI $1.40-4.55)$, weight loss ( $\mathrm{p}<0.0001$, OR $2.85,95 \%$ CI 1.60-5.05), arterial hypertension ( $\mathrm{p}=0.007$, OR $2.90,95 \%$ CI 1.34-6.26), avascular necrosis ( $\mathrm{p}=0.03$, OR 9.11,95\% CI 1.22-68.18), and keratoconjunctivitis ( $\mathrm{p}=0.001$, OR $2.68,95 \%$ CI 1.50-4.78).

Only presence of RF and weight loss were modified after adjustment by age, sex, smoking habits, and HLA GRS $(\mathrm{p}=0.004$, OR $0.33,95 \%$ CI $0.16-0.70$ and $\mathrm{p}=0.002$, OR $2.55,95 \%$ CI 1.41-4.64, respectively; Table 2).

Treatment. We also obtained information on therapies, steroidal, and NSAID drugs. We clearly observed an association between reduced Amerindian ancestry and patients with RA treated with NSAID $(\mathrm{p}=0.001$, OR $0.37,95 \%$ CI $0.20-0.67)$, MTX ( $\mathrm{p}=0.001$, OR $0.35,95 \%$ CI $0.19-0.66$ ), and LEF ( $\mathrm{p}=0.001$, OR $0.16,95 \%$ CI $0.06-0.46$; Table 3), a result that was not modified by age, sex, smoking, or HLA GRS. On the contrary, increased Amerindian ancestry and higher doses of immunosuppressive drugs (AZA: $\mathrm{p}<0.0001$, OR 163.6, 95\% CI 29.73-900.6, and CSA: $\mathrm{p}=0.017$, OR $541.7,95 \%$ CI 3.05-96092.7) and SSZ were observed ( $\mathrm{p}<0.0001$, OR 48.63, 95\% CI 19.02-124.35; Table 3). The association with AZA and SSZ remained highly significant after Bonferroni correction and adjustment for sex, age, smoking, and HLA GRS.

\section{DISCUSSION}

We report for the first time, to our knowledge, that the major manifestations of RA, as well as the number of definitive criteria, are associated with European ancestry or with lower Amerindian ancestry in admixed populations. Our results are of great interest because these may help to determine whether an individual with more genetic European ancestry may be at a higher risk to develop erosions, for instance. On the other hand, we clearly show that age, sex, and smoking do affect the presence of RF and the loss of weight, but not other manifestations. The reason for this is unclear and would mark the delineation between some of the manifestations of RA and genetics versus environmental factors. It has been shown in a large twin study that the presence of anti-CCP independently of the presence of RA was associated with smoking. Also, the association was stronger in individuals with the shared epitope. Smokers homozygous for the shared epitope had the higher risk for RA, but smoking alone was an independent determinant ${ }^{23,24,26,27}$. In agreement, we observe no effect of the GRS for the HLA on the clinical-ancestry associations, suggesting that age, sex, and smoking are far more important variables in the development of RA, despite the strong genetic association of the HLA SE alleles.

While in general in our study there were no differences in smoking habits and ancestry, we did observe an association

Personal non-commercial use only. The Journal of Rheumatology Copyright (C) 2017. All rights reserved 
Table 2. Associations of genetic ancestry with RA manifestations.

\begin{tabular}{|c|c|c|}
\hline Manifestations & $\begin{array}{c}\mathrm{p}_{\text {Bonferroni }} \\
\text { OR }(95 \% \mathrm{CI})\end{array}$ & $\begin{array}{c}\text { P Value Adjusted for Age, Sex, } \\
\text { Smoking, and HLA GRS, } \\
\text { OR ( } 95 \% \text { CI })\end{array}$ \\
\hline \multicolumn{3}{|l|}{ ACR criteria } \\
\hline Morning stiffness & $<0.0001,0.05(0.02-0.12)$ & $<0.0001,0.06(0.02-0.16)$ \\
\hline Rheumatoid factor & $<0.0001,0.22(0.11-0.44)$ & $0.004,0.33(0.16-0.70)$ \\
\hline Subcutaneous nodules & n.s. & n.s. \\
\hline Three or more affected joints & n.s. & n.s. \\
\hline Symmetrical RA & n.s. & n.s. \\
\hline Anti-CCP & n.s. & n.s. \\
\hline Radiographic changes & $<0.0001,0.05(0.03-0.10)$ & $<0.0001,0.06(0.03-0.11)$ \\
\hline \multicolumn{3}{|l|}{ Extraarticular manifestations } \\
\hline Fatigue & n.s. & n.s. \\
\hline Weight loss & $<0.0001,2.85(1.60-5.05)$ & $0.002,2.55(1.41-4.64)$ \\
\hline Fever & n.s. & n.s. \\
\hline Muscle weakness & n.s. & n.s. \\
\hline Muscular atrophy & n.s. & n.s. \\
\hline Osteoporosis & n.s. & n.s. \\
\hline Avascular necrosis & n.s. & n.s. \\
\hline Periungual infarction & n.s. & n.s. \\
\hline Digital infarction & n.s. & n.s. \\
\hline Ulcer & n.s. & n.s. \\
\hline Palpable purpura & n.s. & n.s. \\
\hline Raynaud syndrome & n.s. & n.s. \\
\hline Keratoconjunctivitis & n.s. & n.s. \\
\hline Episcleritis & n.s. & n.s. \\
\hline Scleritis & n.s. & n.s. \\
\hline Scleromalacia & n.s. & n.s. \\
\hline Uveitis & n.s. & n.s. \\
\hline Episcleral nodulosis & n.s. & n.s. \\
\hline Cataract & n.s. & n.s. \\
\hline Glaucoma & n.s. & n.s. \\
\hline Keratopathy & n.s. & n.s. \\
\hline Retinopathy & n.s. & n.s. \\
\hline Pleural effusion & n.s. & n.s. \\
\hline Pleuritis & n.s. & n.s. \\
\hline Interstitial fibrosis & n.s. & n.s. \\
\hline Lung nodules & n.s. & n.s. \\
\hline Caplan syndrome & n.s. & n.s. \\
\hline Bronchiolitis & n.s. & n.s. \\
\hline Arterial hypertension & n.s. & n.s. \\
\hline Pericarditis & n.s. & n.s. \\
\hline Myocarditis & n.s. & n.s. \\
\hline Endocardiac disease & n.s. & n.s. \\
\hline Arrhythmias & n.s. & n.s. \\
\hline Congenic heart failure & n.s. & n.s. \\
\hline Ischemic vascular disease & n.s. & n.s. \\
\hline Venous thrombosis & n.s. & n.s. \\
\hline Peripheral neuropathy & n.s. & n.s. \\
\hline Atlantoaxial subluxation & n.s. & n.s. \\
\hline Neuritis (mono- or poly-) & n.s. & n.s. \\
\hline Anemia & n.s. & n.s. \\
\hline Thrombocytosis & n.s. & n.s. \\
\hline Thrombocytopenia & n.s. & n.s. \\
\hline Eosinophilia & n.s. & n.s. \\
\hline Lymphadenopathy & n.s. & n.s. \\
\hline Renal failure & n.s. & n.s. \\
\hline Rheumatoid vasculitis & n.s. & n.s. \\
\hline Infections & n.s. & n.s. \\
\hline Neoplasia & n.s. & n.s. \\
\hline
\end{tabular}

RA: rheumatoid arthritis; GRS: genetic risk score; ACR: American College of Rheumatology; anti-CCP: anticyclic citrullinated peptide antibodies; n.s.: not significant. 


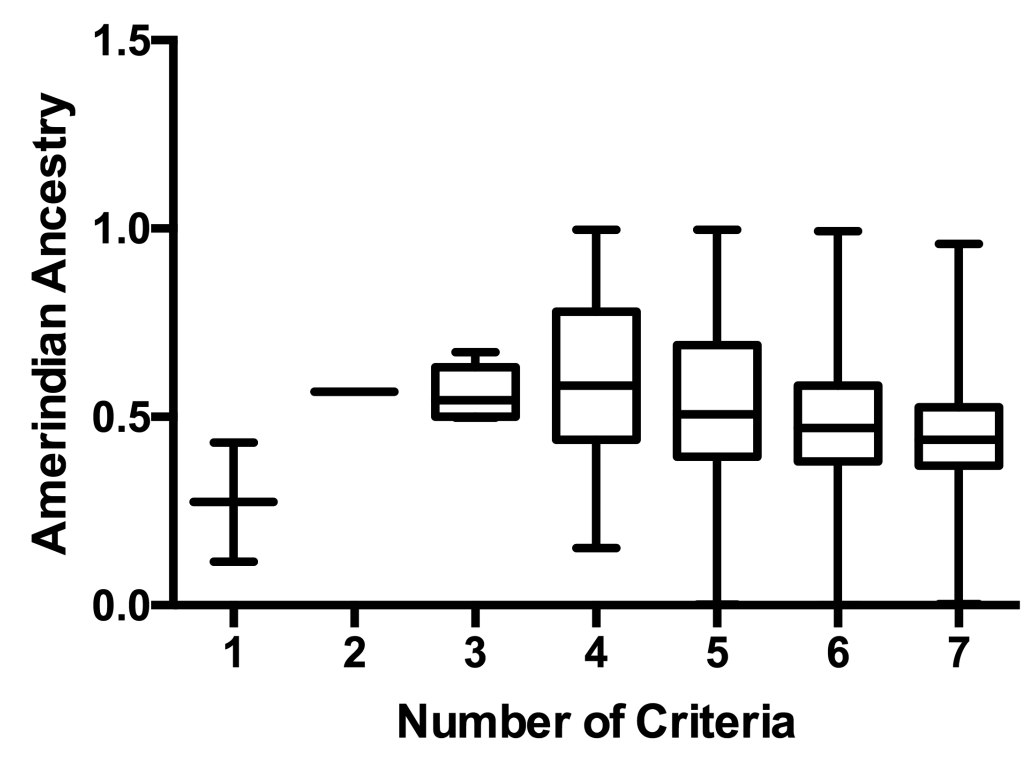

Figure 3. Negative correlation between number of clinical criteria for definite rheumatoid arthritis and proportion of Amerindian ancestry.

Table 3. Effect of genetic ancestry on RA treatment modalities.

\begin{tabular}{lcc}
\hline Treatment & $\mathrm{p}_{\text {Bonferroni }}$, OR $(95 \%$ CI $)$ & $\begin{array}{c}\text { P Value Adjusted for Age, Sex, Smoking, } \\
\text { and HLA GRS, OR (95\% CI) }\end{array}$ \\
\hline $\begin{array}{l}\text { NSAID } \\
\text { Prednisone }\end{array}$ & $0.001,0.37(0.20-0.67)$ & $0.004,0.40(0.21-0.75)$ \\
Hydroxychloroquine & n.s. & n.s. \\
Chloroquine & n.s. & n.s. \\
Methotrexate & n.s. & n.s. \\
Leflunomide & $0.001,0.35(0.19-0.66)$ & $<0.0001,0.19(0.09-0.45)$ \\
Sulfasalazine & $0.001,0.16(0.06-0.46)$ & $0.001,0.11(0.03-0.40)$ \\
Gold salts & $<0.0001,48.6(19.02-124.3)$ & $<0.0001,32.91(11.33-95.60)$ \\
Azathioprine & n.s. & n.s. \\
Minocycline & $<0.0001,163.6(29.73-900.6)$ & $<0.0001,166.42(16.75-1652.92)$ \\
Cyclosporine & n.s. & n.s. \\
Biological agents & n.s. & n.s. \\
Other treatments & n.s. & n.s. \\
\hline
\end{tabular}

RA: rheumatoid arthritis; GRS: genetic risk score; NSAID: nonsteroidal antiinflammatory drugs; n.s.: not significant.

in the individuals (cases and controls jointly) from Peru, where smoking was strongly associated with lower Amerindian ancestry. This result is significant because Peruvian individuals had the highest Amerindian ancestry proportions (up to a mean of $70 \%$ ) of the countries of origin studied. This association would need to be confirmed. However, it suggests that European ancestry and smoking increase the risk for RA, but may also provide support for a European genetic contribution to the habit of smoking itself.

There were, nevertheless, several associations with increased Amerindian ancestry such as fatigue, weight loss, and arterial hypertension, although only weight loss passed stringent multiple testing filters. Further, Amerindian ancestry was also associated with the increased doses of immunosuppressive agents. This is somewhat surprising considering that Amerindian ancestry appears to protect against the higher number of definite RA criteria, and would suggest that the subjectivity in the assessment of the state of the patient may influence the dosage provided by the physician, tending toward a higher dosage in patients who describe fatigue or have weight loss. Of interest, a composite score such as the 28-joint Disease Activity Score was not associated (data not shown) with ancestry, but possibly 1 or 2 of its components (Health Assessment Questionnaire or grip strength) may be associated. Unfortunately, we do not have detailed information on this. Once again, because this study is the first to 
incorporate this type of data to a genetic ancestry determination, it is important to confirm our observations in independent cohorts of patients carefully followed and including genetic, epidemiological, and sociodemographic information.

One of the most interesting aspects of our study is the differentiation between RA and the results from our previous study on $\mathrm{SLE}^{34}$. We basically show that the presence of more RA criteria and of definite RA is associated with European ancestry, while in SLE the presence of renal disease is associated with Amerindian ancestry. How well defined and validated the classic clinical criteria are for ethnicities other than the European is a matter to be taken into consideration, but our results suggest that indeed, RA with the classic and definite criteria is in many ways a disease of European origin possibly brought to the Americas 500 years ago. Hand lesions resembling those of RA are depicted in Flemish art of the $1400 \mathrm{~s}$ and $1500 \mathrm{~s}^{37,38}$. Italian art by Sandro Botticelli ${ }^{39}$ shows a possible juvenile case from 1481, more than 300 years before the disease was originally described by Landré-Beauvais ${ }^{40}$.

\section{ACKNOWLEDGMENT}

The authors thank the anonymous donors who generously contributed the biological material for our study. The authors thank Daniel Villalba and Leonardo Grasso for maintaining the www.NETGENOME.com database through which all data and sample collection have been organized. The authors also thank Farideh Movafagh for technical assistance and Maria Teruel for performing the HLA HiBAG imputation and determination of the genetic risk score.

APPENDIX 1. List of study collaborators. Genomica de Artritis Reumatoide (GENAR): Argentina: Carlos Meineri, Instituto Lucha Antipoliomielítica de Rosario (ILAR), Santa Fé; Susana Roverano, Hospital José María Cullen, Santa Fé; Donna L. González, Hospital J.B. Iturraspe, Santa Fe; Jorge Chemez, Hospital San Martín, Paraná; Veronica Saurit, Francisco Caeiro, Hospital Privado de Córdoba, Córdoba; Norma G. Vila, Maria C. De la Vega, Hospital Cosme Argerich, Buenos Aires; Paula B. Alba, Hospital Italiano de Córdoba, Córdoba; Ana Bertoli, Mariela Ramos, Instituto Reumatológico Strusberg, Córdoba; Cecilia Musumeci, Roberto Haag, Amelia Granel, H.I.G.A. San Martín, La Plata; Jorge A. López, Alicia Testa, H.I.G.A. Oscar E. Alende, Mar del Plata; Alberto Berman, Centro Medico Privado de Reumatología, Tucumán; Dora Lía Vázquez, FUNIPSE, San Miguel de Tucumán; Santiago E. Agüero, Sergio Orellana, Hospital Interzonal San Juan Bautista, Catamarca; Rodolfo Pardo Hidalgo, Hospital G Rawson, San Juan; Enrique Soriano, Cecilia Castel, Lorena Narváez, Hospital Italiano de Buenos Aires, Buenos Aires; Eduardo Mysler, Organización Médica Integral, Buenos Aires; Roberto M. Arana, Centro de Educación Médica e Investigaciones Clínicas, Buenos Aires; José Maldonado Cocco, Instituto de Rehabilitación Psicofísica, Ciudad Autónoma de Buenos Aires; Antonio Mónaco, Mariel Cutri, Hospital Bernardino Rivadavia, Ciudad Autónoma de Buenos Aires; María del Rosario Maliandi, Hospital de Clínicas de Buenos Aires, Buenos Aires. Perú: Jorge Mariano Cucho, Hospital Nacional Guillermo Almenara Irigoyen, Lima. Chile: Cecilia Trejo and Jorge Saavedra, Hospital San Juan de Dios, Santiago de Chile; Carmen Medina (RN), Reumatología Hospital San Borja-Arriarán, Santiago de Chile. Mexico: Marco González, Unidad de Reumatología Hospital General de México; Eduardo Liceaga, Mexico City; Jacqueline Rodriguez Amado and Mario A. Garza-Elizondo, Hospital Universitario de Nuevo León, Nuevo León, Monterrey; Josefina Munguía-Rojas, CEIBAC, S.C. Guadalajara.

\section{REFERENCES}

1. Stahl EA, Wegmann D, Trynka G, Gutierrez-Achury J, Do R, Voight BF, et al; Diabetes Genetics Replication and Meta-analysis Consortium; Myocardial Infarction Genetics Consortium. Bayesian inference analyses of the polygenic architecture of rheumatoid arthritis. Nat Genet 2012;44:483-9.

2. Okada Y, Terao C, Ikari K, Kochi Y, Ohmura K, Suzuki A, et al. Meta-analysis identifies nine new loci associated with rheumatoid arthritis in the Japanese population. Nat Genet 2012;44:511-6.

3. Kurreeman FA, Stahl EA, Okada Y, Liao K, Diogo D, Raychaudhuri S, et al. Use of a multiethnic approach to identify rheumatoid-arthritis-susceptibility loci, 1p36 and 17q12. Am J Hum Genet 2012;90:524-32.

4. Eyre S, Bowes J, Diogo D, Lee A, Barton A, Martin P, et al; Biologics in Rheumatoid Arthritis Genetics and Genomics Study Syndicate; Wellcome Trust Case Control Consortium. High-density genetic mapping identifies new susceptibility loci for rheumatoid arthritis. Nat Genet 2012;44:1336-40.

5. Kurreeman F, Liao K, Chibnik L, Hickey B, Stahl E, Gainer V, et al. Genetic basis of autoantibody positive and negative rheumatoid arthritis risk in a multi-ethnic cohort derived from electronic health records. Am J Hum Genet 2011;88:57-69.

6. Chen R, Stahl EA, Kurreeman FA, Gregersen PK, Siminovitch KA, Worthington J, et al. Fine mapping the TAGAP risk locus in rheumatoid arthritis. Genes Immun 2011;12:314-8.

7. Stahl EA, Raychaudhuri S, Remmers EF, Xie G, Eyre S, Thomson BP, et al; BIRAC Consortium; YEAR Consortium. Genome-wide association study meta-analysis identifies seven new rheumatoid arthritis risk loci. Nat Genet 2010;42:508-14.

8. Karlson EW, Chibnik LB, Kraft P, Cui J, Keenan BT, Ding B, et al. Cumulative association of 22 genetic variants with seropositive rheumatoid arthritis risk. Ann Rheum Dis 2010;69:1077-85.

9. Korman BD, Seldin MF, Taylor KE, Le JM, Lee AT, Plenge RM, et al. The chromosome 7q region association with rheumatoid arthritis in females in a British population is not replicated in a North American case-control series. Arthritis Rheum 2009;60:47-52.

10. Gregersen PK, Amos CI, Lee AT, Lu Y, Remmers EF, Kastner DL, et al. REL, encoding a member of the NF-kappaB family of transcription factors, is a newly defined risk locus for rheumatoid arthritis. Nat Genet 2009;41:820-3.

11. Cui J, Taylor KE, Destefano AL, Criswell LA, Izmailova ES, Parker A, et al. Genome-wide association study of determinants of anti-cyclic citrullinated peptide antibody titer in adults with rheumatoid arthritis. Mol Med 2009;15:136-43.

12. Lee HS, Lee AT, Criswell LA, Seldin MF, Amos CI, Carulli JP, et al. Several regions in the major histocompatibility complex confer risk for anti- j-antibody positive rheumatoid arthritis, independent of the DRB1 locus. Mol Med 2008;14:293-300.

13. Graham RR, Cotsapas C, Davies L, Hackett R, Lessard CJ, Leon $\mathrm{JM}$, et al. Genetic variants near TNFAIP3 on 6q23 are associated with systemic lupus erythematosus. Nat Genet 2008;40:1059-61.

14. Plenge RM, Seielstad M, Padyukov L, Lee AT, Remmers EF, Ding $\mathrm{B}$, et al. TRAF1-C5 as a risk locus for rheumatoid arthritis - a genomewide study. N Engl J Med 2007;357:1199-209.

15. Plenge RM, Padyukov L, Remmers EF, Purcell S, Lee AT, Karlson $\mathrm{EW}$, et al. Replication of putative candidate-gene associations with rheumatoid arthritis in $>4,000$ samples from North America and Sweden: association of susceptibility with PTPN22, CTLA4, and PADI4. Am J Hum Genet 2005;77:1044-60.

16. Carmona L, Villaverde V, Hernandez-Garcia C, Ballina J, Gabriel R, Laffon A; EPISER Study Group. The prevalence of rheumatoid arthritis in the general population of Spain. Rheumatology 2002;41:88-95

17. Cardiel MH, Rojas-Serrano J. Community based study to estimate

Personal non-commercial use only. The Journal of Rheumatology Copyright $\odot$ 2017. All rights reserved 
prevalence, burden of illness and help seeking behavior in rheumatic diseases in Mexico City. A COPCORD study. Clin Exp Rheumatol 2002;20:617-24

18. Peláez-Ballestas I, Sanin LH, Moreno-Montoya J, Alvarez-Nemegyei J, Burgos-Vargas R, Garza-Elizondo M, et al; Grupo de Estudio Epidemiológico de Enfermedades Músculo Articulares (GEEMA). Epidemiology of the rheumatic diseases in Mexico. A study of 5 regions based on the COPCORD methodology. J Rheumatol Suppl. 2011 Jan;86:3-8.

19. Alvarez-Nemegyei J, Peláez-Ballestas I, Sanin LH, Cardiel MH, Ramirez-Angulo A, Goycochea-Robles MV. Prevalence of musculoskeletal pain and rheumatic diseases in the southeastern region of Mexico. A COPCORD-based community survey. J Rheumatol Suppl. 2011 Jan;86:21-5

20. López Herráez D, Martínez-Bueno M, Riba L, García de la Torre I, Sacnún M, Goñi M, et al. Rheumatoid arthritis in Latin Americans enriched for Amerindian ancestry is associated with loci in chromosomes 1, 12, and 13, and the HLA class II region. Arthritis Rheum 2013;65:1457-67.

21. Diogo D, Kurreeman F, Stahl EA, Liao KP, Gupta N, Greenberg JD, et al; Consortium of Rheumatology Researchers of North America; Rheumatoid Arthritis Consortium International. Rare, low-frequency, and common variants in the protein-coding sequence of biological candidate genes from GWASs contribute to risk of rheumatoid arthritis. Am J Hum Genet 2013;92:15-27.

22. Raychaudhuri S, Sandor C, Stahl EA, Freudenberg J, Lee HS, Jia X, et al. Five amino acids in three HLA proteins explain most of the association between $\mathrm{MHC}$ and seropositive rheumatoid arthritis. Nat Genet 2012;44:291-6.

23. Morgan AW, Thomson W, Martin SG; Yorkshire Early Arthritis Register Consortium, Carter AM; UK Rheumatoid Arthritis Genetics Consortium, Erlich HA, Barton A, et al. Reevaluation of the interaction between HLA-DRB1 shared epitope alleles, PTPN22, and smoking in determining susceptibility to autoantibody-positive and autoantibody-negative rheumatoid arthritis in a large UK Caucasian population. Arthritis Rheum 2009;60:2565-76.

24. Mei L, Li X, Yang K, Cui J, Fang B, Guo X, et al. Evaluating gene X gene and gene $\mathrm{x}$ smoking interaction in rheumatoid arthritis using candidate genes in GAW15. BMC Proc 2007;Suppl 1:S17.

25. Lee HS, Irigoyen P, Kern M, Lee A, Batliwalla F, Khalili H, et al. Interaction between smoking, the shared epitope, and anti-cyclic citrullinated peptide: a mixed picture in three large North American rheumatoid arthritis cohorts. Arthritis Rheum 2007;56:1745-53.

26. Kallberg H, Padyukov L, Plenge RM, Ronnelid J, Gregersen PK, van der Helm-van Mil AH, et al; Epidemiological Investigation of Rheumatoid Arthritis study group. Gene-gene and gene-environment interactions involving HLA-DRB1, PTPN22, and smoking in two subsets of rheumatoid arthritis. Am J Hum Genet 2007;80:867-75

27. Majka DS, Holers VM. Cigarette smoking and the risk of systemic lupus erythematosus and rheumatoid arthritis. Ann Rheum Dis 2006;65:561-3.

28. van der Helm-van Mil AH, Wesoly JZ, Huizinga TW. Understanding the genetic contribution to rheumatoid arthritis. Curr Opin Rheumatol 2005;17:299-304.

29. Scher JU, Ubeda C, Equinda M, Khanin R, Buischi Y, Viale A, et al. Periodontal disease and the oral microbiota in new-onset rheumatoid arthritis. Arthritis Rheum 2012;64:3083-94.

30. Hart JE, Kallberg H, Laden F, Bellander T, Costenbader KH, Holmqvist M, et al. Ambient air pollution exposures and risk of rheumatoid arthritis: results from the Swedish EIRA case-control study. Ann Rheum Dis 2012;72:888-94.

31. Pischon N, Pischon T, Kröger J, Gülmez E, Kleber BM, Bernimoulin JP, et al. Association among rheumatoid arthritis, oral hygiene, and periodontitis. J Periodontol 2008;79:979-86.

32. Okada Y, Wu D, Trynka G, Raj T, Terao C, Ikari K, et al; RACI consortium; GARNET consortium. Genetics of rheumatoid arthritis contributes to biology and drug discovery. Nature 2014;506:376-81.

33. Sanchez E, Webb RD, Rasmussen A, Kelly JA, Riba L, Kaufman $\mathrm{KM}$, et al. Genetically determined Amerindian ancestry correlates with increased frequency of risk alleles for systemic lupus erythematosus. Arthritis Rheum 2010;62:3722-9.

34. Sánchez E, Rasmussen A, Riba L, Acevedo-Vasquez E, Kelly JA, Langefeld CD, et al. Impact of genetic ancestry and sociodemographic status on the clinical expression of systemic lupus erythematosus in American Indian-European populations. Arthritis Rheum 2012;64:3687-94.

35. Cortes A, Brown MA. Promise and pitfalls of the Immunochip. Arthritis Res Ther 2011;13:101.

36. Zheng X, Shen J, Cox C, Wakefield JC, Ehm MG, Nelson MR, and Weir BS. HIBAG - HLA genotype imputation with attribute bagging. Pharmacogenomics J 2014;14:192-200

37. Dequeker J. Arthritis in Flemish paintings (1400-1700). Br Med J 1977;1:1203-5.

38. Dequeker J, Rico H. Rheumatoid arthritis-like deformities in an early 16th-century painting of the Flemish-Dutch school. JAMA 1992;268:249-51

39. Alarcón-Segovia D, Laffón A, Alcocer-Varela J. Probable depiction of juvenile arthritis by Sandro Botticelli. Arthritis Rheum 1983;26:1266-8

40. Short CL. The antiquity of rheumatoid arthritis. Arthritis Rheum 1974;17:193-205. 